Review

\title{
Childhood Epilepsy: An Update on Diagnosis and Management
}

\author{
Khaled Saad \\ Department of Pediatrics, Faculty of Medicine, University of Assiut, Assiut 71516, Egypt
}

Article history

Received: 23-10-2014

Revised: 25-11-2014

Accepted: 12-01-2015

\begin{abstract}
Within the past few years there is a rapid expansion in our understanding of epilepsy. The development of new anti-epileptic drugs and refinements to epilepsy surgery are widening the therapeutic options for epilepsy. In addition, the classification of the epilepsies continues to evolve based on an increased understanding of the molecular genetics of the condition and this includes the recognition of possible novel epilepsy syndromes. This review considers some of these exciting developments, as well as addressing the essential features of the diagnosis, investigations, management and impact of epilepsy in childhood.
\end{abstract}

Keywords: Children, Epilepsy, Seizure, Anti-Epileptic Drugs

\section{Introduction}

Epilepsy is a common heterogeneous neurological problem in children. It exerts a significant physical, psychological, economic and social toll on children and their caregivers. Fifty million people have epilepsies globally; more than half of them are children. In the USA; between 25,000 and 40,000 children will have a first non-febrile seizure each year. The problem is further compounded in developing countries as they add about $75-80 \%$ of new cases of epilepsy (Guerrini, 2006; Tamber and Mountz, 2012; Sharma, 2013). The seizures and epilepsies in children are extremely diverse, differing markedly in age of onset, seizure characteristics, associated comorbidities, treatment and prognosis. Given that there is a shortage of pediatric epileptologists practicing around the world, it is impossible for all children with recurrent seizures to receive their care from subspecialists. Rather, such children often need to rely on pediatric neurologists, general pediatricians and/or family practitioners provide the care they need and deserve. Without a firm understanding of the complexities of childhood epilepsy, it may be not possible for such physicians to always make an accurate diagnosis and plan an effective treatment strategy. So it is important for the general pediatrician to be aware of the evaluation and management of these patients (Tamber and Mountz, 2012; Sharma, 2013). Also, pediatricians and practitioners should have a role in preventing epilepsy by minimizing neurological insults in early infancy and childhood. In addition, there is a need to focus on primary health care providers by providing them guidelines for optimal practices, rational therapy and counseling (Aylwad, 2008; Tamber and Mountz, 2012; Sharma, 2013).

\section{Definitions}

A seizure is defined as an excessive burst of abnormal synchronized neuronal activity affecting small or large neuronal networks that results in clinical manifestations that are sudden, transient and usually brief. Epilepsy is defined as a disorder of the brain characterized by any of the following conditions: (1) At least two unprovoked (or reflex) seizures occurring $>24 \mathrm{~h}$ apart, (2) One unprovoked (or reflex) seizure and a probability of further seizures similar to the general recurrence risk (at least $60 \%$ ) after two unprovoked seizures, occurring over the next 10 years and 3) Diagnosis of an epilepsy syndrome (Hauser and Banerjee, 2008; Tamber and Mountz, 2012; Fisher et al., 2014). Provoked seizure is a seizure that occurs in reaction to an acute, transient condition affecting the brain. Provoking factors include, but are not limited to, head trauma, stroke, intracranial infections, acute metabolic disruptions (e.g., hypoglycemia, anoxia) and acute drug or toxin poisoning (Hauser and Banerjee, 2008; Tamber and Mountz, 2012).

\section{Incidence}

Epileptic seizures affect 1-2\% of the population and $4 \%$ of children. Developing countries have higher prevalence due to the poorer perinatal care and standards of nutrition and public hygiene and the greater risk of brain injury, cerebral infection or other symptomatic cerebral conditions. Incidence of seizures is age 
dependent. The highest incidence rate $(100$ per 100,000$)$ is observed in the first year of life, declining to approximately 20 cases per 100,000 per year in adolescence. Childhood epilepsy has a prevalence of approximately $0.5-0.8 \%$ and comprises a heterogeneous group of disorders, including a variety of epilepsy syndromes that range in severity from benign to progressive and catastrophic. Focal epilepsies predominate $(59-63 \%)$ than generalized epilepsy (12-29\%). In about $20 \%$ classification may change on follow up (Hauser and Banerjee, 2008; Sharma, 2013; Cross et al., 2013).

\section{ILAE Classifications of Seizures, Epilepsy}

The ILAE Commission on Classification and Terminology released a revision of the previous system in 2010 (Berg et al., 2010). The report is not a new classification, but it organizes the current knowledge (Table 1).

\section{Mode of Seizure Onset}

In the 2010 ILAE proposal, the mode of seizure onset is divided into three basic groups based upon clinical and EEG data: Focal, generalized and unknown (e.g., Epileptic spasms) (Berg et al., 2010):

- Generalized epileptic seizures are conceptualized as those that originating at some point within and rapidly engaging, bilaterally distributed networks, which can be subcortical or cortical structures, but do not essentially, include the entire cortex. In addition, generalized seizures can be asymmetric (Berg et al., 2010; Berg and Scheffer, 2011)

- The term focal has replaced partial epileptic seizures, which are conceptualized as originating within one hemisphere. They may be localized or widely distributed. Focal seizures may originate in subcortical structures. No natural classification for focal seizures exists; focal seizures should be described according to their manifestations (e.g., dyscognitive, focal motor) (Berg et al., 2010; Berg and Scheffer, 2011)

\section{Underlying Type of Cause (Etiology)}

The terms idiopathic, symptomatic and cryptogenic, are now not used. Instead of the previous terms the following three terms (genetic, structural/metabolic and unknown) and their associated concepts are recommended (Berg et al., 2010; Berg and Scheffer, 2011):

\section{Genetic}

The concept of genetic epilepsy is that the epilepsy is the direct result of a known or presumed genetic $\operatorname{defect}(s)$ in which seizures are the core symptom of the disorder. This attribution must be supported by specific forms of evidence. The knowledge regarding the genetic contributions may derive from specific molecular genetic studies that have been well replicated and even become the basis of diagnostic tests (e.g., SCN1A and Dravet syndrome) or the evidence for a central role of a genetic component may come from appropriately designed family studies.

\section{Structural/Metabolic}

There is a distinct other structural or metabolic condition or disease that has been demonstrated to be associated with an increased risk of developing epilepsy. Structural lesions include acquired disorders such as stroke, trauma and infection. They may also be of genetic origin (e.g., Tuberous sclerosis).

\section{Unknown}

The nature of the underlying cause is as yet unknown; it may have a genetic basis (e.g., A previously unrecognized channelopathy) or it may be the result of an unrecognized structural or metabolic disorder. Epilepsies of unknown cause are those, which in the past were termed "cryptogenic".

\section{Types of Seizures}

\section{Generalized Seizures}

Generalized seizures are seizures that rapidly engaging, bilaterally distributed networks, which can be subcortical or cortical structures and in which consciousness is impaired from the onset. The previously used terminology of seizure classification, "secondary generalized" and "secondarily generalized," are no longer recognized in the ILAE classification, the term changed to "focal seizure evolving to a bilateral, convulsive seizure. Generalized seizures are subdivided into multiple types (Table 1) (Browne and Holmes, 2008; Berg et al., 2010; Mikati, 2011; Tamber and Mountz, 2012; Piña-Garza and Fenichel, 2013; Rudzinski et al., 2013):

\section{Absence Seizures}

Absence seizures are generalized seizures, indicating bihemispheric involvement, clinically and on the EEG. Absence Seizures are characterized by a sudden onset behavioral arrest, a blank stare, unresponsiveness and sometimes a brief upward rotation of the eyes. The duration is typically a few seconds to half a minute. There is little to no postictal confusion and the patient typically resumes the activity he/she was doing prior to the seizures. This seizure type is also referred to as simple typical absence. 
Table 1. ILAE classification of seizures* (Berg et al., 2010)

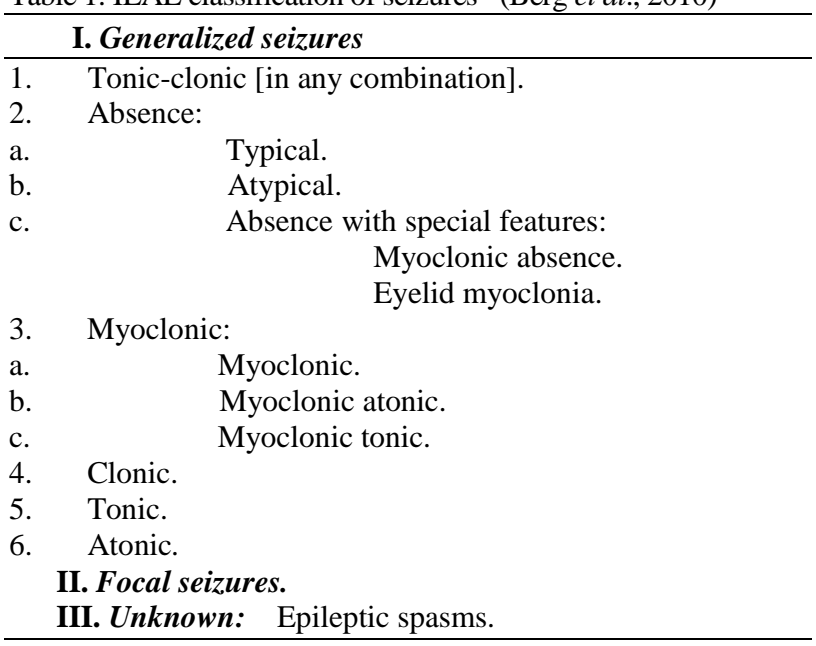

*Seizure that cannot be clearly diagnosed into one of the preceding categories should be considered unclassified until further information allows their accurate diagnosis.

ILAE: International league against epilepsy

Atypical absence seizures have associated myoclonic components and tone changes of the head and body. The EEG of absence seizures is pathognomonic, there are bilaterally synchronous and symmetric paroxysms of spike-and-wave complexes at a frequency of $3 \mathrm{~Hz}$ appear concurrently with the clinical seizure. Hyperventilation is a potent activator of typical absence seizures. It almost always activates the discharge. Failure to induce an absence seizure with several trials of hyperventilation of 3 to 5 min duration in an untreated patient makes the diagnosis of absence seizures unlikely (Mikati, 2011; Tamber and Mountz, 2012; Rudzinski et al., 2013).

\section{Myoclonic Seizures}

Myoclonic Seizures are characterized by sudden, brief (less than 350 millisecond), irregular and shock like contractions that may be generalized or confined to the face and trunk, or to one or more extremities, or even to individual muscles or groups of muscles. It can be single or repetitive, varying in severity from an almost imperceptible twitch to a severe jerking. They can be symmetric or asymmetric. They tend to occur close to sleep onset and upon awakening from sleep. Myoclonic seizures can be a feature of some idiopathic generalized epilepsies (Juvenile Myoclonic Epilepsy), symptomatic generalized epilepsies (Myoclonic Atonic Epilepsy), the progressive myoclonic epilepsies (Lafora Disease) and infantile spasms. Myoclonus can be positive or negative. Negative myoclonus refers to the brief loss of postural tone when the body part is held against gravity. There is no post-ictal confusion and consciousness is not impaired with single myoclonic jerks. Myoclonic seizures can occur in clusters and may evolve into clonic-tonic-clonic seizures, with resultant loss of consciousness and postictal confusion. The ictal EEG pattern is characterized by brief generalized polyspikes or polyspikes and wave discharges which corresponds to the myoclonic jerk (Tamber and Mountz, 2012; Rudzinski et al., 2013).

\section{Clonic Seizures}

Clonic Seizures are typically seen in neonates and young children. They are characterized by repetitive rhythmic clonic jerks (1-2 Hz) with impairment of consciousness and a short post-ictal phase. They can lead into a clonic-tonic-clonic seizure. It is thought that the repetitive discharges are due to rhythmic excitatory discharges from the cortex. The ictal EEG demonstrates generalized polyspikes and wave discharges or generalized fast activity (Engel, 2006; Tamber and Mountz, 2012; Rudzinski et al., 2013).

\section{Tonic Seizures}

Tonic Seizures are brief seizures consisting of sudden onset of increased tone in the extensor muscles with altered consciousness. The duration of these seizures is longer than the myoclonic seizures. Tonic seizures frequently begin with tonic contraction of the neck muscles, leading to fixation of the head in an erect position, widely opened eyes and jaw clenching or mouth opening. Contraction of the respiratory and abdominal muscles often follows and may lead to a high-pitched cry and brief periods of apnea. Asymmetric tonic seizures vary, from a slight rotation of the head to a tonic contraction of all the musculature of one side of the body. They are one of the common seizure types in patients with Lennox-Gastaut syndrome. The interictal EEG of patients with tonic seizures is usually quite abnormal, consisting of slowing of the background, with multifocal spikes, sharp waves and bursts of irregular spike-and-wave activity. The ictal EEG usually consists of bilateral synchronous spikes of 10 to $25 \mathrm{~Hz}$ of medium to high voltage, with a frontal accentuation (Berg et al., 2010; Mikati, 2011; Piña-Garza and Fenichel, 2013).

\section{Tonic-Clonic (Grand Mal) Seizures}

Tonic clonic seizures are the classic form of epileptic seizure, with altered consciousness followed by tonic extension and then clonic convulsive movements of all four extremities. Generalized Tonic-Clonic seizures (GTCs) are the commonest seizures of childhood. The onset may occur at any time after the neonatal period. It may be a manifestation of primary generalized epilepsy, following focal seizures with a focal onset or alternating with other seizure forms. They may be associated with aura, suggesting a focal origin of the epileptic discharge (Mikati, 2011; Tamber and Mountz, 2012; Piña-Garza and Fenichel, 2013). EEG during the seizure shows 
generalized repetitive spikes in the tonic phase and then periodic spikes in the clonic phase. The clonic phase is usually obscured by movement artifacts. As the seizure ends there is slowing of the background and amplitude attenuation. In between attacks, brief generalized spikes or spike-wave discharges that are polymorphic in appearance may occur (Browne and Holmes, 2008; Mikati, 2011; Piña-Garza and Fenichel, 2013).

\section{Atonic Seizures}

Atonic Seizures may manifest as the classic drop attack, in which all postural tone is suddenly lost, or more subtle changes, such as a slight head drop or bowing at the knees. Atonic seizures consist of the sudden loss of muscle tone, which may be confined to a group of muscles, such as the neck, resulting in a head drop, or it may involve all trunk muscles, leading to a fall to the ground. Atonic seizures begin suddenly and without warning and cause the patient, if standing, to fall quickly to the floor. Because total lack of tone may occur, the patient has no means of self-protection and injuries often occur. Consciousness is impaired during the fall, although the patient may regain alertness immediately on hitting the floor. The correlate of tonic seizures in the EEG includes an electrodecremental response. An electrodecremental response is a sudden generalized drop in amplitude of the EEG. This pattern may evolve into slow spike-and-wave complexes or diffuse polyspikes (Browne and Holmes, 2008; Mikati, 2011; Piña-Garza and Fenichel, 2013).

\section{Focal Seizures}

Focal Seizures are those that originate within networks limited to one hemisphere, which may stay confined or spread to other areas of the brain with corresponding localized EEG discharge. Focal seizures are classified as focal seizure without impairment of consciousness (previously referred to as simple partial seizure) and focal seizures with impaired consciousness correspond to what have previously been called complex partial seizures. Either type of focal seizures may evolve into a secondarily generalized seizure (Browne and Holmes, 2008; Berg et al., 2010; Mikati, 2011; Rudzinski et al., 2013). Consciousness is defined as the "degree of awareness and/or responsiveness of the patient to externally applied stimuli". Responsiveness refers to the ability of the patient to respond to external stimuli and awareness refers to the recall of events occurring during the ictal period (Rudzinski et al., 2013). Focal seizures manifest themselves in many different forms, depending on which area of the cortex is involved in the onset and spread of the ictal discharge. Focal seizures are further subdivided primarily on the basis of the clinical signs and symptoms and the EEG localization. In patients with focal seizures, the interictal EEG includes focal spikes, sharp waves and slowing unilaterally or bilaterally (Browne and Holmes, 2008; Mikati, 2011; Piña-Garza and Fenichel, 2013; Rudzinski et al., 2013).

Examples of Focal Seizures Include (Browne and Holmes, 2008; Mikati, 2011; Piña-Garza and

Fenichel, 2013; Rudzinski et al., 2013)

- Focal motor seizures can originate in the precentral gyrus or spread to the precentral gyrus from neighbouring cortical areas. They can remain focal, causing right hand clonic activity, or can spread or "march" along the motor strip involving different areas of the motor homunculus. This type of seizure is known as a "Jacksonian seizure" and often clinically manifests as clonic activity originating in the hand and then marching up the ipsilateral arm, shoulder, face and leg. After a focal motor seizure, postictal weakness (Todd's paralysis) can last for minutes to hours. Also the focal seizures may manifest as versive movement (turning of the eyes, head and/or trunk), vocalization, or stop of speech

- Sensory seizures can be manifest by paraesthesias ("pins and needles"), numbness, warmth, or electrical shock-like sensations which can also spread like Jacksonian seizures (a sensory Jacksonian march), feelings of distortion of an extremity, vertigo, gustatory sensation, olfactory symptoms, auditory symptoms and visual phenomena such as flashing lights

- Autonomic seizures may include an epigastric "rising" sensation (a common aura with medial temporal lobe epilepsy), such as vomiting, sweating, piloerection, pupil dilation, pallor, flushing, borborygmi and incontinence

- Focal seizures without impairment of consciousness may also manifest higher cortical, psychic symptoms, including dysplasia, feelings of familiarity ("deja-vu"), distortions of time, affective changes (particularly fear), illusions and formed hallucinations. Such seizures are often referred to as auras

- During focal seizures with impairment of consciousness, the patient may have a variety of repetitive purposeless movements that are referred to as motor automatisms. It occurs as oral-buccal movements (chewing, swallowing, sucking), complex motor phenomena, including bicycling and kicking movements, pulling at clothes, waving of the arms and running, jumping and spinning. Automatism develops after the loss of consciousness and may persist into the postictal phase. Automatism has no localizing significance and child has complete amnesia of the event. Automatism is a common feature in infants and children, occurring in approximately $50-75 \%$ of cases; the older the child, 
the greater is the frequency of automatism. Such seizures involve regions of both hemispheres, thus explaining the impaired consciousness and the more complex and bilateral motor symptomatology

\section{Epilepsy Syndromes in Children}

An epileptic syndrome is defined as a complex of signs and syndromes that define a unique epilepsy condition with different etiologies. A syndrome must involve more than just a seizure type. One important characteristic of syndromes is the characteristic age at onset. The most recent revision recommended that the term syndrome be restricted to a clinical entity that is reliably identified by a cluster of electroclinical characteristics (Engel, 2006; Berg et al., 2010).

\section{Epileptic Syndromes in Children}

\section{Neonatal Epileptic Syndromes}

\section{Benign Familial Neonatal Epilepsy (BFNE)}

This syndrome has been reported to occur in 14.4 per 100,000 live births. Benign familial neonatal epilepsy was previously referred to as benign familial neonatal convulsions. This rare, dominantly inherited disorder is due to mutations affecting voltage-gated potassium channel genes (KCNQ2, KCNQ3). Affected infants are usually full term and appear normal at birth. In $80 \%$ of cases, seizures start on the second or third day of life, although some infants may develop seizures later in the first month of life. The seizures are typically clonic, but often preceded by a tonic component. They are more often unilateral, but can also be bilateral. The interictal EEG is usually normal. Spontaneous resolution typically occurs within 2 to 6 months. There is a slight increase in the risk of later epilepsy (11-15\%) (Berg et al., 2010; Ottman et al., 2010; Daroff et al., 2012).

\section{Early Myoclonic Encephalopathy (EME)}

Early (neonatal) Myoclonic Encephalopathy (EME) has been referred to in the literature as early myoclonic encephalopathy, myoclonic encephalopathy with neonatal onset, neonatal myoclonic encephalopathy and early myoclonic encephalopathy with epilepsy and has been most closely associated with Aicardi syndrome. Early myoclonic encephalopathy is characterized by focal myoclonus involving limbs or face that is very frequent, sometimes continuous, shifting from one area to another. Generalized massive myoclonus may appear shortly thereafter, as will focal motor seizures. Epileptic spasms typically develop later in the course of the disorder. Neurological status is abnormal, either at birth or with the development of clinical seizures, but most infants are hypotonic. The EEG is helpful in diagnosis of
EME. The background activity is suppression-burst pattern. The pattern may be present only in sleep. The prognosis is poor. There is increased mortality in the first few years of life and survivors have significant developmental delay (Aicardi and Goutieres, 1978; Berg et al., 2010; Ottman et al., 2010).

\section{Ohtahara Syndrome}

Early Infantile Epileptic Encephalopathy (EIEE) has also been referred to as Ohtahara syndrome. The onset is within the first two to three months of life. At the onset the neurologic examination is abnormal with developmental delay, spasticity and motor asymmetries. Ohtahara syndrome is characterized by tonic spasms as the predominant seizure type, but a third of affected infants also have other seizure types, including focal motor seizures, hemiconvulsions and generalized motor seizures. The background EEG pattern in Ohtahara syndrome is suppression-burst with relatively prolonged bursts (2-6 sec) and shorter periods of suppression $(3-5 \mathrm{sec})$. The EEG may evolve from the initial suppression-burst pattern to a hypsarrhythmia pattern; typical of West syndrome. The prognosis is poor, half of the patients die in infancy; survivors have severe neurologic impairment (Berg et al., 2010; Ottman et al., 2010; Yamatogi and Ohtahara, 2003).

\section{DEND Syndrome}

DEND syndrome (developmental delay, epilepsy, neonatal diabetes) is a very rare, generally severe form of neonatal diabetes mellitus characterized by a triad of developmental delay, epilepsy and neonatal diabetes. It is caused by an activating mutation in the KCNJ11 gene, which encodes the Kir6.2 subunit of the potassium ion channel. Oral sulfonylurea therapy appears to be more effective than insulin in controlling hyperglycemia and can also lead to improved seizure control and psychomotor development (Hattersley and Ashcroft, 2005; Shimomura et al., 2007).

\section{Epileptic Syndromes with Onset During Infancy and Childhood}

Numerous epilepsy syndromes characteristically have their onset in infancy and childhood. Most of these syndromes are extremely rare (Berg et al., 2010; Daroff et al., 2012).

\section{Epilepsy of Infancy with Migrating Focal Seizures}

Epilepsy of infancy with migrating focal seizures is a rare, infantile epileptic encephalopathy characterized by normal early development, refractory focal seizures arising independently from both hemispheres and severe psychomotor retardation. The diagnostic criteria include the presence of (1) normal development before seizure 
onset, (2) onset before 6 months, (3) migrating focal motor seizures at onset, (4) multifocal seizures becoming intractable to conventional antiepileptic drugs, (5) no identified etiology and (6) profound psychomotor delay (Berg et al., 2010; Sharma et al., 2011).

\section{West Syndrome}

Infantile Spasms (IS) is an age-specific convulsive disorder of infancy and early childhood. The triad of epileptic spasms, arrest or deterioration of psychomotor development and a characteristic EEG pattern called hypsarhythmia; is known as West syndrome. West syndrome has a later age at onset; the peak incidence of onset $(50-77 \%)$ is between 3 and 7 months of age. The disorder is heterogeneous in its etiology. Approximately two-thirds of infants have brain lesions. Psychomotor development may be abnormal prior to onset, but there is a clear deterioration after onset (Mikati, 2011; Piña-Garza and Fenichel, 2013; Daroff et al., 2012; Pellock et al., 2010).

Epileptic spasms are usually the initial manifestation. They tend to occur in clusters, sometimes multiple times a day. Three clinical types of spasms have been recognized as flexor, extensor and mixed flexorextensor. Most infants have more than one type of spasm. Flexor type consists of sudden flexion of the neck, trunk, arms and legs and contraction of the abdominal muscles. Extensor type consists of abrupt extension of the neck and trunk, with abduction or adduction of the arms or legs. Mixed flexor-extensor spasms usually consist of flexion of the neck, trunk and arms and extension of the legs. Less commonly, they involve flexion of the legs and extension of the arms (Mikati, 2011; Piña-Garza and Fenichel, 2013; Daroff et al., 2012). Hypsarrhythmia is characterized by high-voltage disorganized EEG activity with slow waves and multifocal spikes and sharp waves punctuated by periods of generalized attenuation (Daroff et al., 2012). The prognosis is variable, with a small portion of patients recovering quickly without complications. This is more likely to happen in the absence of brain pathology. Otherwise, the prognosis is unfavorable, with more than $70 \%$ developing mental retardation and other cognitive disabilities (Piña-Garza and Fenichel, 2013; Daroff et al., 2012).

\section{Myoclonic Epilepsy in Infancy (MEI)}

Myoclonic seizures may begin in the first year of life. Myoclonic jerks may be focal, multifocal, or generalized and are more likely to be flexor than extensor. Myoclonus is termed epileptic when it occurs with a cortical epileptic form discharge, usually a generalized spike and wave discharge or spikes/sharp waves over the motor cortex (MEC, 1997; Daroff et al., 2012).

\section{Benign Familial Infantile Epilepsy}

Benign familial infantile epilepsy is an autosomal dominant epilepsy syndrome characterized by febrile seizures in an otherwise normal infant beginning at about six months of age. Seizures typically subside by two years of age and psychomotor development is normal (Vigevano, 2005).

\section{Dravet Syndrome}

Dravet syndrome, also called severe myoclonic epilepsy of infancy, is usually due to a de novo mutation affecting the SCN1A gene encoding the $\alpha_{1}$ sodium channel subunit. De novo mutations account for about $70-95 \%$ of cases. The typical clinical presentation is that a previously normally developing infant has febrile status epilepticus at around 6 months of age and then recurrent generalized or shifting hemiclonic seizures are seen, often triggered by fever. After 1 year of age, other seizure types appear, including myoclonic seizures, absence seizures and complex partial seizures as well as atonic seizures at times. The seizures are drug resistant and may be exacerbated by some sodium channel blockers such as carbamazepine and lamotrigine. The EEG becomes increasingly abnormal with age. Abnormalities include focal, multifocal and/or generalized epileptiform activity and changes in background activity. The prognosis is poor; the majority of individuals develop intellectual disability and at times ataxia and spasticity (Kassaï et al., 2008; Daroff et al., 2012).

\section{Genetic Epilepsy with Febrile Seizures Plus}

A group of genetic epilepsy syndromes that often begin during the first year of life, referred to as "genetic epilepsy with febrile seizures plus" (GEFS+), are characterized by multiple febrile seizures, generalized tonic-clonic seizures and other seizure types including absences, myoclonic seizures and focal seizures (Daroff et al., 2012).

\section{Lennox-Gastaut Syndrome}

Lennox-Gastaut Syndrome (LGS) is classified as an epileptic encephalopathy. The age of onset is usually before age 8 with a peak age of onset between 3-5 years of age. Rarely, the disorder can present in early adulthood. The syndrome is characterized by a triad of multiple seizure types (tonic and atypical absence are the most common), slow spike and wave on EEG (1-2.5 Hz) and cognitive dysfunction. It may evolve from West syndrome. Tonic seizures are considered a prerequisite for the diagnosis. Atypical absence and atonic seizures are also common. Myoclonic, generalized tonic-clonic, unilateral clonic and partial seizures can occur less frequently. Nonconvulsive status epilepticus can occur in $>50 \%$ of 
patients and involves near continuous atypical absence seizures interrupted by brief tonic seizures. The diagnosis may be difficult to do at first because not all features of the syndrome may be present. The seizures are typically refractory to medical treatment (Rudzinski et al., 2013; Daroff et al., 2012).

\section{Myoclonic Atonic Epilepsy}

Myoclonic atonic epilepsy is a syndrome similar to but milder than Lennox-Gastaut syndrome that usually does not have tonic seizures or polyspike bursts in sleep. The prognosis is more favorable than that for Lennox Gastaut syndrome (Mikati, 2011).

\section{Epileptic Encephalopathy with Continuous Spike-and- Wave during Sleep and Landau Kleffner Syndrome}

The common features of the related conditions of epileptic encephalopathy with Continuous Spike-andWave during Sleep (CSWS) and Landau Kleffner Syndrome (LKS) are a decline in cognitive function in association with an EEG pattern of continuous spikeand-wave activity during slow wave sleep. In both conditions the associated seizures are often easy to control and the predominant clinical manifestations are related to the EEG abnormality in sleep. In Landau Kleffner syndrome, the cognitive decline is specifically in the area of speech. The condition is often called acquired epileptic aphasia. This disorder typically appears between 2 and 8 years of age, with a peak between 5 and 7 years. The most common initial manifestation is verbal auditory agnosia. The language disturbance will usually progress despite good control of clinical seizures. In fact, clinical seizures may not even occur in about a quarter of patients. The evolution is variable. Spontaneous remissions may occur within the first year. CSWS differs from LKS in that a larger proportion of individuals have preexisting neurological abnormalities and the cognitive regression is more likely to be global and associated with motor impairments (Browne and Holmes, 2008; Mikati, 2011; Daroff et al., 2012; Piña-Garza and Fenichel, 2013).

\section{Absence Epilepsy}

\section{Juvenile Absence Epilepsy}

Juvenile Absence Epilepsy (JAE) is classified as an idiopathic generalized epilepsy. The age of onset is typically at or after puberty between the ages of 10 17. Unlike in Childhood Absence Epilepsy (CAE) where absence seizures can occur hundreds of times per day, absence seizures in JAE may only occur sporadically. There is less impairment of consciousness with absence seizures in JAE compared to absences in CAE. Patients with JAE can have generalized tonic-clonic seizures (usually upon awakening), myoclonic seizures and even absence status epilepticus. The ictal EEG pattern resembles that of CAE ( $3 \mathrm{~Hz}$ spike and wave) but the discharges tend to vary slightly in frequency (usually $>3 \mathrm{~Hz}$ ), are more irregular and include more polyspike discharges. There is a strong genetic component with linkage to chromosomes 5, 8, 18 and 21. The response to antiepileptic medication is usually excellent (Daroff et al., 2012; Rudzinski et al., 2013).

\section{Childhood Absence Epilepsy}

Childhood Absence Epilepsy (CAE) is a form of idiopathic, genetically-determined, generalized epilepsy that is characterized by absence seizures and in $10 \%$ of cases, generalized tonic-clonic seizures. Absence seizures start between the ages of 4 and 10 years of age with the peak age of occurrence 6 to 7 years. Seizures occur many times a day. The etiology of childhood absence epilepsy is genetic with complex multifactorial inheritance. $15-45 \%$ of children have a positive family history and monozygotic twins have a $75 \%$ concordance rate. The majority (65-70\%) of children with childhood absence epilepsy have remission of seizures in adolescence; good prognostic signs are earlier age at onset and absent other types of seizures (Daroff et al., 2012; Rudzinski et al., 2013).

\section{Juvenile Myoclonic Epilepsy}

Juvenile Myoclonic Epilepsy (JME) is also known as juvenile myoclonic epilepsy of Janz. The age of onset is in the mid-teens between the ages of 12-18. Patients may present with myoclonic jerks upon awakening in the morning. Patients may first ignore the myoclonic jerks, often attributing them to clumsiness. Sometimes the diagnosis is not made until the patient has a generalized tonic-clonic seizure. The myoclonus usually involves the neck, shoulders, arms, or legs with the upper extremities being most frequently affected. Consciousness is usually not impaired during the myoclonic seizures. Generalized tonic clonic and absence seizures are also seen. Generalized tonic clonic and absence seizures are also seen. Generalized tonic-clonic seizures may also occur in the morning upon awakening and can be triggered by sleep deprivation, alcohol and stress. Often, several myoclonic jerks may precede a generalized tonic-clonic seizure, which is known as a clonic-tonic-clonic seizure. Approximately 50\% of patients can be photosensitive. The diagnosis of the condition is based on the clinical history and EEG, which shows generalized irregular 4- to 6-Hz spikeand-wave activity occurring in bursts. The EEG is more likely to record discharges after awakening (Mikati, 2011; Daroff et al., 2012; Rudzinski et al., 2013). 


\section{Rasmussen's Encephalitis}

Rasmussen's encephalitis is a form of chronic encephalitis that manifests with unilateral intractable focal seizures, epilepsia partialis continua and progressive hemiparesis of the affected side, with progressive atrophy of the contralateral hemisphere. The etiology is usually unknown. Some cases have been attributed to cytomegalovirus and others to anti-NMDA receptor autoantibodies (Mikati, 2011).

\section{Benign Epilepsy Syndromes with Focal Seizures}

Benign partial epilepsies of childhood are electroclinical syndromes that occur in developmentally and neurologically normal children and have a self-limited course, remitting prior to adulthood (Browne and Holmes, 2008; Mikati, 2011; Piña-Garza and Fenichel, 2013):

\section{Childhood Epilepsy with Centrotemporal Spikes}

The most common such syndrome is benign childhood epilepsy with centrotemporal spikes (benign rolandic epilepsy) which typically starts during childhood and is outgrown in adolescence. The child typically wakes up at night owing to a focal seizure causing buccal and throat tingling and tonic or clonic contractions of one side of the face, with drooling and inability to speak but with preserved consciousness. EEG shows a typical broad-based centrotemporal spikes that are markedly increased in frequency during drowsiness and sleep. MRI is normal. Patients respond very well to AEDs. In some patients who only have rare and mild seizures treatment might not be needed (Browne and Holmes, 2008; Mikati, 2011; Piña-Garza and Fenichel, 2013).

\section{Benign Epilepsy with Occipital Spikes}

Benign epilepsy with occipital spikes can occur in early childhood (Panayiotopoulos type) and manifests with a unique seizure type that has prominent autonomic features including vomiting and pallor. The seizures are usually nocturnal and last more than five minutes, or they appear in later childhood (Gastaut type) with frequent seizures with prominent visual symptoms (hallucinations, blindness) and migraine headaches. The mean age of onset is between eight and nine years. EEG reveals occipital spikes, activated by eye closure. Both are typically outgrown in a few years (Mikati, 2011; Piña-Garza and Fenichel, 2013).

\section{Nocturnal Autosomal Dominant Frontal Lobe Epilepsy}

Nocturnal autosomal dominant frontal lobe epilepsy has been linked to acetylcholine-receptor gene mutations and manifests with nocturnal seizures with dystonic posturing that respond promptly to carbamazepine. Several other less-frequently familial benign epilepsy syndromes with different localizations have also been described, some of which occur exclusively or predominantly in adults (Browne and Holmes, 2008; Mikati, 2011; Piña-Garza and Fenichel, 2013).

\section{Management of Childhood Epilepsy}

\section{Diagnosis and Differential Diagnosis}

Diagnostic tasks in epilepsy management include establishing a seizure diagnosis and an etiologic diagnosis and identification of precipitating factors. This is accomplished by a combination of history taking, physical Examination, Electroencephalography (EEG) and laboratory examinations (Piña-Garza and Fenichel, 2013).

\section{Seizure Diagnosis}

The first step in managing a child for whom a diagnosis of epilepsy is possible is establishing definitively whether the patient has epilepsy or not. Patients who are erroneously diagnosed with epilepsy will be unnecessarily subjected to many medications that may produce serious side effects. Specific differential diagnostic entities that must be differentiated from seizures include the conditions that mimic epilepsy; (Table 2, 3). Confirming or ruling out epilepsy not only prevents unnecessary treatment and exposure to interventions, but also reduces patient and family anxiety and possibly unnecessary stigma (Obeid and Mikati, 2007; Mikati, 2011; Glauser and Loddenkemper, 2013).

\section{History (Table 4):}

The best way to diagnose which type of seizure in a patient is to observe a seizure, although the physician usually does not have the opportunity to do so. Often, the most important differential diagnostic information is contained in the history gathered from the patient, reliable observers, or both. The history for seizure diagnosis should include exact details of events before, during and after the seizure, obtained from the patient and observers. Focal seizure symptoms and signs (motor, sensory, autonomic, psychic); alteration of consciousness; automatisms; tonic movements, clonic movements, or both; tongue biting; incontinence and postictal behavior are important details. The duration, time of occurrence (e.g., On awakening, when drowsy, during sleep) and frequency of seizures also are important. For example, tonic-clonic seizures occurring during the first few hours of sleep are usually secondarily generalized, while tonic-clonic seizures occurring upon awakening are usually primarily generalized. Past or current occurrence of other seizure types (especially myoclonic, or absence) should be obtained. 
Table 2. Conditions that mimic seizures according to age (Obeid and Mikati, 2007)

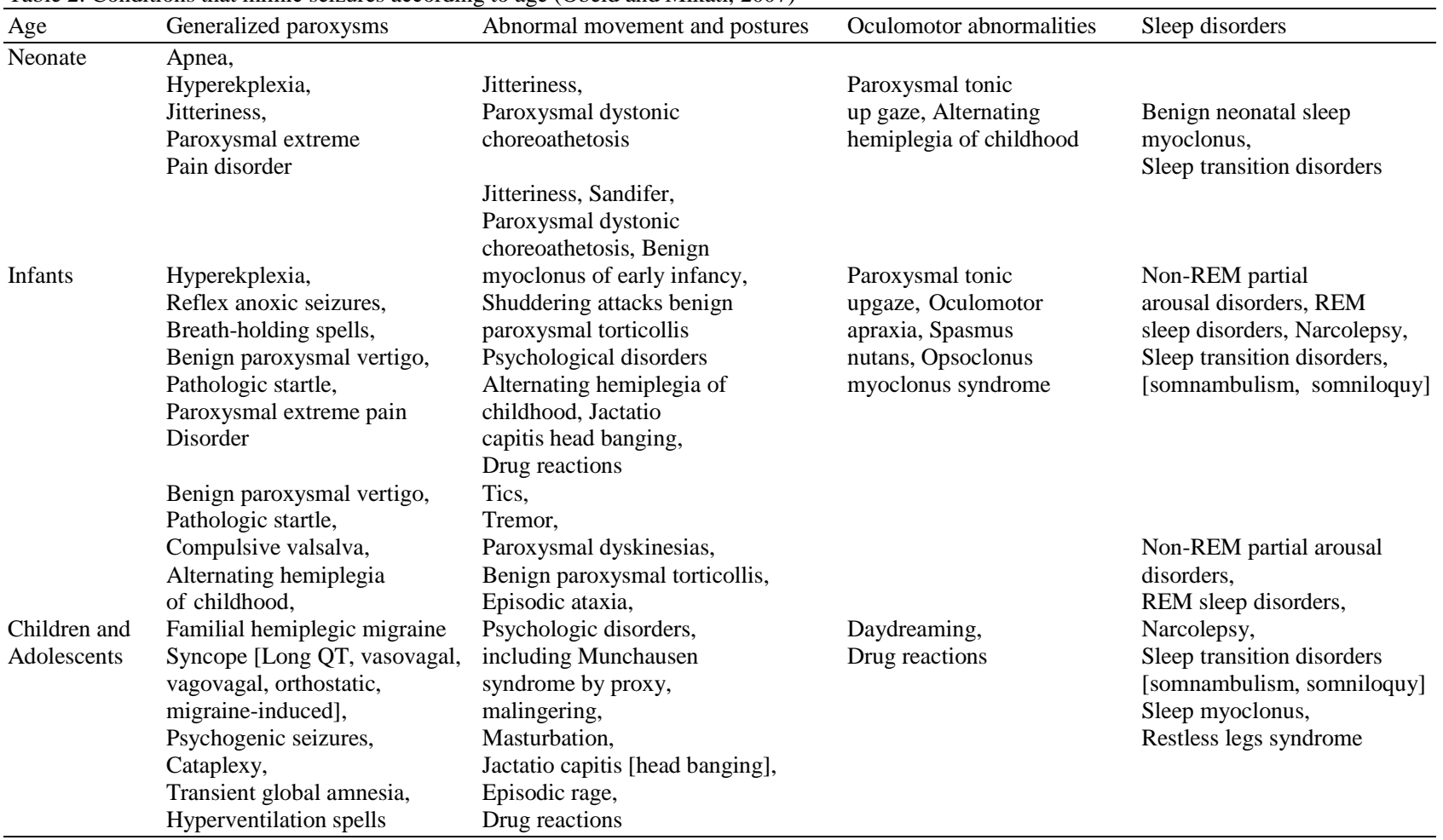

Table 3. Differences between generalized seizures and some generalized paroxysms that present with drop attacks or mimic generalized tonic-clonic seizures (Obeid and Mikati, 2007)

\begin{tabular}{|c|c|c|c|c|}
\hline & Precipitators & Prodrome & Ictal event & Postictal period \\
\hline I. Generalized seizures & Sleep deprivation & None & $\begin{array}{l}\text { Loss of consciousness: } \\
2-3 \text { min. Synchronous } \\
\text { bilateral movements. } \\
\text { Tongue-biting }\end{array}$ & $\begin{array}{l}\text { Delayed recovery with } \\
\text { postictal depression }\end{array}$ \\
\hline
\end{tabular}

II. Syncope with or

without anoxic seizures

(a) Neural

Vasovagal

Fatigue, emotional

stress, dehydration

Reflex anoxic seizures

Minor bump to the head

Loss of consciousness:

Seconds. White discoloration

in reflex anoxic seizures

Vagovagal

Hyperekplexia

Respiratory

(b) Cardiac

III. Psychogenic seizures

Suggestion

Psychologic stress
Vomiting, swallowing

Blurring of vision, tinnitus, dizziness Crying in breathholding episodes auditory and tactile stimuli Injury, anger

Exercise
None

\author{
Loss of consciousness: \\ Seconds. Blue discoloration \\ Loss of consciousness: Seconds \\ White discoloration \\ Loss of consciousness: >2-3 \\ min. Gradual onset. \\ Asynchronous, flailing limb No postictal \\ movements. Variable features \\ between attacks. No injury
} Rapid recovery with
no postictal depression
The history for etiology should include questions regarding family history of epilepsy, head trauma, birth complications, febrile convulsions, middle ear and sinus infections (which may erode through bone and cause cerebral focus) and symptoms of malignancy.
The history for precipitating factors should include factors such as fever, anxiety, sleep deprivation, hyperventilation, flickering lights, or television (Sharma, 2013; Browne and Holmes, 2008; Glauser and Loddenkemper, 2013; Chitre, 2013). 
Table 4. Essential information that should be obtained during the history-taking (Chitre, 2013)

1. Detailed description and sequence of events occurring in the attack [s]. Were they aware of surroundings? Any obvious motor phenomenon? Were they stiff or floppy? Was the movement repetitive or sustained?

2. How did the attack[s] start? What were they doing? Was there any warning? What was the first thing that happened? Was there a behaviour change?

3. Was there a change in colour or breathing pattern? Was there any responsiveness? Could the event be interrupted?

4. Were there any symptoms after the attack [s]? How long did it take to full recovery? Any recollection of events?

5. What are the frequency and duration? Any particular time of the day?

6. What were the general circumstances around the attack[s]? Possible precipitants? Are they more common in certain situations?

7. Medical history.

8. Pregnancy, birth and neonatal history.

9. Development, current school performance.

10. Family history of epilepsy and learning difficulties and social history.

\section{Physical Examination}

Clinical, neurological examination and fundus examination are very important in evaluation of epilepsy. The physical examination should be directed toward uncovering evidence of past or recent head trauma; infections of the ears and sinuses; congenital abnormalities (e.g., hemiatrophy, stigmata of tuberous sclerosis); focal or diffuse neurologic abnormalities; and signs of malignancy. Other findings may be useful in uncovering evidence of focal brain dysfunction indicative of focal epilepsy e.g., Facial asymmetry, asymmetry of thumb size (indicates contralateral cerebral damage during infancy or childhood), drift or pronation of outstretched hands, dystonic postures when walking on sides of feet, or naming difficulty (left temporal dysfunction). Finally, $3 \mathrm{~min}$ of vigorous hyperventilation usually produces absence seizures in untreated absence seizure patients (Browne and Holmes, 2008; Sharma, 2013; Glauser and Loddenkemper, 2013).

\section{Investigations}

About $80 \%$ of community epilepsy can be managed without any investigations. These are not for making a diagnosis of epilepsy, but for confirming diagnosis and establish the cause (Chitre, 2013). Metabolic screen and lumbar puncture (for opening pressure, cell counts, protein, glucose, cytology, culture and serology) should be performed if infection or malignancy is suspected (Browne and Holmes, 2008).

\section{Electroencephalography}

The EEG is a helpful diagnostic tool in the investigation of a seizure disorder. It confirms the presence of abnormal electrical activity giving information regarding the type of seizure disorder and discloses the location of the seizure focus. Both routine (paper tracing) and digital recording techniques are in regular use. EEG done within $24 \mathrm{~h}$ of the seizure was found to have more yields of epileptiform discharges as compared to an EEG done later, 51 versus 34\%. A normal EEG does not exclude epilepsy, because $40 \%$ of epileptic patients have a normal EEG. Prolonged video EEG monitoring is reserved for complicated cases of protracted and unresponsive seizures (King et al., 1998; Browne and Holmes, 2008; Sharma, 2013).

\section{Radiology}

Neuro-imaging should be performed when a health care provider suspects a serious structural brain lesion in patients with new focal deficits, persistent altered mental status, fever, recent trauma, persistent headache, history of cancer, history of anticoagulation, or suspicion of acquired immunodeficiency syndrome. Also, it is indicated in seizures in early infancy, focal seizures, developmental delay and in developing countries to rule out granuloma. MRI is better than CT; however CT is sufficient in detecting inflammatory granulomas in the majority of cases (Browne and Holmes, 2008; Sharma, 2013).

\section{Synthesis of Data}

By combining history, physical examination and EEG information, the health care provider should be able to determine (a) whether the patient's events are seizures or not and (b) the patient's seizure type(s). If this cannot be done, additional history (e.g., Additional witnesses) or additional EEG (e.g., Longterm EEG monitoring) information, or both, should be obtained. If all possible information has been gathered and the diagnosis remains uncertain, the health care provider usually is forced to act on the basis of available history. If the history strongly suggests a recurrent seizure type, a therapeutic trial of antiepileptic medication appropriate for the seizure type is usually begun. If the history does not strongly suggest recurrent seizures, observation without medication is the usual plan. Seizure type combined with additional information from history, physical examination, EEG and laboratory tests often allow determination of the patient's specific epilepsy syndrome. This determination assists with selection of therapy and counseling regarding prognosis and familial occurrence (Browne and Holmes, 2008). 


\section{Management of First Unprovoked Seizure}

After a first unprovoked seizure, the chances of a second seizure range from 30 to $55 \%$ over the next 2 to 5 years. Mostly a developmentally normal child with first idiopathic generalized tonic clonic seizure does not require long term Antiepileptic Drugs (AED) (Glauser and Loddenkemper, 2013). Some clinicians initiate treatment after the first unprovoked seizure if the risk of injury and harm from seizures is extremely high, as in; focal seizure (after excluding benign focal seizures), myoclonic seizures and absence seizures, the first episode is status epilepticus and underlying structural lesion, e.g., Cortical dysplasia and severe parental anxiety (Glauser and Loddenkemper, 2013; Appleton et al., 2012; Glauser et al., 2006).

\section{Indications for Treatment}

After a second unprovoked seizure, the chances of a third unprovoked seizure are 80 to $90 \%$ within 2 years if treatment is not initiated. Therefore, treatment after the second unprovoked seizure is recommended (Glauser and Loddenkemper, 2013).

There is no ideal AED. In most cases it has to be individualized. The AED of choice depends on the classification of the seizure, determined by the history and EEG findings. The goal for every patient should be the use of only one drug with the fewest possible side effects for complete seizure control and the best quality of life. The drug is increased slowly until seizure control is accomplished or until undesirable side effects develop. Monotherapy in appropriate dose controls seizures in 70$80 \%$ cases. If seizures are uncontrolled with the first drug, choose alternate monotherapy and gradually withdraw the first drug. If seizures are still not controlled, refer to a child neurologist. The patient may require polytherapy, ketogenic diet or surgery. Before labeling drug failure, always check compliance; rule out conditions that mimic epilepsy (Table 2 and 3 ) and progressive neurological disorders (Browne and Holmes, 2008; Mikati, 2011; Appleton et al., 2012; Sharma, 2013; Glauser and Loddenkemper, 2013).

Physicians should be familiar the AED (Table 5) and its side effects and should monitor the child on a regular basis. Routine serum monitoring of anticonvulsant levels is not recommended because the practice is not cost effective. The indications for AED monitoring, including: (1) At the beginning of AED therapy to confirm that the drug level is within the therapeutic range; (2) for noncompliant children and caregivers; (3) during status epilepticus; (4) during accelerated growth spurts; (5) for patients on polytherapy (6) for patients with intractable seizures or seizures that have changed in type; (7) for manifestations of drug toxicity; and (8) for children with hepatic or renal disease (Browne and Holmes, 2008; Sharma, 2013).
Routine blood screening (CBC, liver function tests) is not indicated during AED therapy. Blood tests are ordered only when clinically indicated (Browne and Holmes, 2008; Mikati, 2011).

\section{AED Selection and Management}

The selection of the first (or subsequent) antiepileptic medication is affected by a combination of patientspecific and AED- specific factors. Patient-specific factors include the child's disease characteristics (e.g., seizure type, epilepsy type and epilepsy syndrome) along with their commodities, communications, age, gender and ability to swallow pills. AED-specific factors include the drug's effectiveness and/or efficacy for a specific seizure type or epilepsy syndrome, its pharmacokinetic characteristics, dose dependent adverse effects, idiosyncratic reactions, chronic toxicities, teratogenicity and carcinogenicity (Glauser and Loddenkemper, 2013). If complete seizure control is accomplished by AED, a minimum of 2 seizure-free years is an adequate and safe period of treatment for a patient with no risk factors. AED is required for longer duration in epileptic syndromes and if there are multiple risk factors for recurrence. Prominent risk factors include age greater than 12 years at onset, neurologic dysfunction (motor handicap or mental retardation), a history of prior neonatal seizures and numerous seizures before control is achieved (Appleton et al., 2012; Sharma, 2013; Glauser and Loddenkemper, 2013).

In order to assess response to treatment, information on the baseline seizure frequency and intervals between initial seizures is crucial. Tracking response to seizures is important, either with paper diaries or with online seizuretracking tools (Glauser and Loddenkemper, 2013).

When the decision is made to discontinue the drug, the weaning process should occur in 3-6 months, because abrupt withdrawal may cause status epilepticus. Most epilepsies remit; relapse is reported in $11-41 \%$, particularly during the first 6 months- 2 years after discontinuation of AED. Restart previous AED, most patients will remit again. The risk factors for relapses, including: Epilepsies with structural brain lesions, abnormal neurological signs and abnormal EEG (Browne and Holmes, 2008; Sharma, 2013; Cross et al., 2013).

Treatment Options of Seizures in Children (Browne and Holmes, 2008; Gupta et al., 2010; Mikati, 2011; Appleton et al., 2012; Sharma, 2013; Glauser and Loddenkemper, 2013)

\section{Epilepsy with Generalized Tonic Clonic Seizures}

For a child of any age, the experts recommended beginning with at least two and possibly three trials of monotherapy before trying at least two-three combinations of 2 AED. 
Table 5. Antiepileptic drugs and pediatric dosing information

\begin{tabular}{|c|c|c|c|c|c|}
\hline Drug & Specific epilepsy indications & $\begin{array}{l}\text { Dose }[\mathrm{mg} / \mathrm{kg} \text { body] } \\
\text { weight/ day] }\end{array}$ & Side effects & Monotherapy & Adjunctive therapy \\
\hline Valproic acid & Wide spectrum of action & $\begin{array}{l}10-60 \text { [in } 2-3 \\
\text { divided dose] }\end{array}$ & $\begin{array}{l}\text { Nausea, weight loss, } \\
\text { alopecia, } \\
\text { hepatotoxicity }\end{array}$ & $\geq 2$ years & $\geq 2$ years \\
\hline Carbamazepine & $\begin{array}{l}\text { Focal, GTC and mixed } \\
\text { types of seizures. Exacerbates } \\
\text { myoclonic and absence seizure }\end{array}$ & $\begin{array}{l}10-30 \text { [in } 2 \\
\text { divided dose] }\end{array}$ & $\begin{array}{l}\text { Ataxia, diplopia, rash, } \\
\text { school performance worsening }\end{array}$ & No age limitations & No age limitations \\
\hline Ethosuximide & Absence epilepsy & $\begin{array}{l}20-30 \text { [in } 2 \\
\text { divided dose] }\end{array}$ & $\begin{array}{l}\text { Abdominal discomfort, hiccups, } \\
\text { headaches, sedation }\end{array}$ & No age limitations & \\
\hline Phenobarbital & $\begin{array}{l}\text { Focal seizures and } \\
\text { GTC seizures }\end{array}$ & $\begin{array}{l}<5 \mathrm{yr}, 3-5 \\
>5 \mathrm{yr}, 2-3\end{array}$ & $\begin{array}{l}\text { Sedation, drowsiness, } \\
\text { hyperactivity, irritability, } \\
\text { dysarthria, cognitive impairment }\end{array}$ & No age limitations & No age limitations \\
\hline Phenytoin & $\begin{array}{l}\text { GTC and focal } \\
\text { [psychomotor and temporal lobe] } \\
\text { seizures. Exacerbates } \\
\text { myoclonic and absence seizure }\end{array}$ & $\begin{array}{l}<3 \mathrm{yr}, 8-10 \\
>3 \mathrm{yr}, 4-7 \text { in } 2 \\
\text { divided dose }\end{array}$ & $\begin{array}{l}\text { Poor seizure control fluctuating } \\
\text { drug level, gum } \\
\text { hyperplasia, hirsutism }\end{array}$ & No age limitations & No age limitations \\
\hline Vigabatrin & $\begin{array}{l}\text { Monotherapy in treatment of } \\
\text { infantile spasms [West- Syndrome], } \\
\text { combination treatment for resistant } \\
\text { focal epilepsy with or without } \\
\text { secondary generalization }\end{array}$ & $\begin{array}{l}150-200 \text { Daily } \\
\text { or twice daily }\end{array}$ & $\begin{array}{l}\text { Visual field defects [irreversible], } \\
\text { diplopia, nystagmus, } \\
\text { sedation, dizziness, ataxia, } \\
\text { cognitive and behavioral } \\
\text { disturbances, paraesthesia }\end{array}$ & No age limitations & No age limitations \\
\hline Lamotrigine & $\begin{array}{l}\text { Monotherapy in focal seizures, } \\
\text { primary and secondarily GTC } \\
\text { seizures } \\
\text { Adjunctive therapy for seizures } \\
\text { associated with therapy-refractory } \\
\text { Lennox-Gastaut syndrome. } \\
\text { Precipitates myoclonic seizures. } \\
\text { Stop drug if rash occurs }\end{array}$ & $\begin{array}{l}0.2-15 \text { in } 2 \\
\text { divided dose } \\
\text { Slow titration }\end{array}$ & $\begin{array}{l}\text { Skin rash, dizziness, ataxia, } \\
\text { Stevens- Johnson syndrome }\end{array}$ & $\geq 12$ years & $\geq 12$ years \\
\hline Felbamate & $\begin{array}{l}\text { Adjunctive treatment of } \\
\text { Lennox -Gastaut Syndrome, } \\
\text { not indicated for first line treatment }\end{array}$ & $\begin{array}{l}30-60 \text { in } 2 \\
\text { divided doses }\end{array}$ & $\begin{array}{l}\text { insomnia, dizziness, headache, } \\
\text { diplopia, aplastic anemia, } \\
\text { hepatic failure, weight loss }\end{array}$ & Unlicensed & $\geq 4$ years \\
\hline Gabapentin & $\begin{array}{l}\text { Monotherapy in focal } \\
\text { seizures with and } \\
\text { without secondary generalization, } \\
\text { adjunctive therapy for partial } \\
\text { seizures with and without } \\
\text { secondary generalization }\end{array}$ & $\begin{array}{l}30-60 \\
3 \text { times daily }\end{array}$ & $\begin{array}{l}\text { Somnolence, dizziness, ataxia, } \\
\text { Fatigue blurred vision, diplopia, } \\
\text { rash, acne, impotence, aggressive } \\
\text { behavior, weight gain }\end{array}$ & $\geq 12$ years & $\geq 3$ years \\
\hline Tiagabine & $\begin{array}{l}\text { Adjunctive therapy for } \\
\text { focal seizures with and } \\
\text { without secondary generalization }\end{array}$ & $\begin{array}{l}15-45 \text { in } 2 \\
\text { divided doses }\end{array}$ & $\begin{array}{l}\text { Sedation, dizziness, depression, } \\
\text { nausea, vomiting, diarrhea, } \\
\text { bruising }\end{array}$ & Unlicensed & $\geq 12$ years \\
\hline Topiramate & $\begin{array}{l}\text { Monotherapy with new diagnosed } \\
\text { epilepsy or conversion to } \\
\text { monotherapy, adjunctive therapy } \\
\text { for focal seizures with or } \\
\text { without secondarily } \\
\text { generalized seizures, primary } \\
\text { GTC seizures, seizures associated } \\
\text { with Lennox-Gastaut syndrome }\end{array}$ & $\begin{array}{l}\text { Initial dose } 0.5-1 \\
\text { Maintenance } \\
\text { dose 5-9 }\end{array}$ & $\begin{array}{l}\text { Anorexia, weight loss, behavior, } \\
\text { changes, hyperthermia, } \\
\text { renal stone, acidosis }\end{array}$ & $\geq 2$ years & $\geq 2$ years \\
\hline Levetiracetam & $\begin{array}{l}\text { Monotherapy in newly } \\
\text { diagnosed epilepsy, adjunctive } \\
\text { therapy in the treatment of } \\
\text { focal-onset seizures with or } \\
\text { without secondary generalization }\end{array}$ & $\begin{array}{l}10 \text { Increase } \\
\text { weekly to } \\
15-45 \text { in } 2 \\
\text { divided doses }\end{array}$ & Sedation, behavior problem & $\geq 16$ years & $\geq 4$ years \\
\hline Oxcarbazepine & $\begin{array}{l}\text { Monotherapy or adjunctive therapy } \\
\text { for focal seizures with or } \\
\text { without secondarily generalized } \\
\text { seizures tonic-clonic }\end{array}$ & $\begin{array}{l}20-40 \\
\text { [in } 2 \text { divided } \\
\text { doses }]\end{array}$ & $\begin{array}{l}\text { Sedation, headache, ataxia, } \\
\text { hyponatremia [rare] }\end{array}$ & $\geq 6$ years & $\geq 6$ years \\
\hline
\end{tabular}

If combination therapy with 2 agents is not effective, the experts would then try a combination of 3 AED. Among the available agents, the experts considered Valproate monotherapy is the first line drug. Lamotrigine can be used as an alternate drug.

Focal and secondary generalized tonic and clonic seizures: They can be treated with oxcarbazepine, carbamazepine, phenobarbital, topiramate, valproic acid, lamotrigine, Clobazam, clonazepam, or levetiracetam. Oxcarbazepine, levetiracetam, carbamazepine (USA) or valproate (Europe) are often used first.

\section{Benign Childhood Epilepsy with Centro-Temporal Spikes (Benign Rolandic Epilepsy)}

No treatment in infrequent seizures. Carbamazepine, Oxcarbazepine and Valproate are the treatment of choice in cases with frequent seizures. 


\section{Absence Epilepsies}

Absence seizures are most often initially treated with Ethosuximide, which is as effective as and less toxic than valproate and more effective than lamotrigine. Alternative drugs of first choice are lamotrigine and valproate, especially if generalized tonic-clonic seizures coexist with absence seizures. Patients resistant to Ethosuximide might still respond to valproate or to lamotrigine. In absence seizures, the EEG is usually helpful in monitoring the response to therapy and is often more sensitive than the parents' observations in detecting these seizures. The EEG often normalizes when complete seizure control is achieved. For patients with juvenile absence epilepsy the first line drug is Valproate, if failed, then the experts considered Lamotrigine as treatment of choice for the next option.

\section{Epilepsy with Myoclonic Seizures}

In adolescent males, Valproate is the treatment of choice, with Lamotrigine another first-line option; for juvenile myoclonic epilepsy in adolescent females, Lamotrigine is the treatment of choice, with Valproate another first-line option. Topiramate and Levetiracetam are other options.

\section{Dravet Syndrome}

Dravet syndrome is usually treated with valproate and benzodiazepines such as clonazepam; the ketogenic diet can also be useful in patients with this syndrome. In some countries Clobazam and stiripentol are available and these appear to result more commonly in successes, particularly if used in combination with valproate. Other medications include zonisamide and topiramate. Lamotrigine has been reported to exacerbate seizures in Dravet syndrome and other myoclonic epilepsies.

\section{West Syndrome}

Infantile spasms is best treated with Adrenocorticotropic Hormone (ACTH). There are several protocols that range in dose from high to intermediate to low. The initial ACTH dose in one highdose protocol is $150 \mathrm{IU} / \mathrm{m}^{2} /$ day of ACTH gel intramuscularly in 2 divided doses for one week. During the 2 nd week, the dose is $75 \mathrm{IU} / \mathrm{m}^{2} /$ day in 1 daily dose for 1 week. For the $3 r d$ week, the dose is $75 \mathrm{IU} / \mathrm{m}^{2}$ every other day for 1 week. ACTH is gradually tapered over the next 9 weeks. Synthetic ACTH has also been used: Synacthen Depot intramuscular $0.25 \mathrm{mg} / \mathrm{ml}$ or $1 \mathrm{mg} / \mathrm{ml}$ is used; $1 \mathrm{mg}$ is considered to have the potency of $100 \mathrm{IU}$ in stimulating the adrenal. ACTH is generally thought to offer an added advantage over prednisone or other steroids alone. Vigabatrin was approved by the FDA for use in children with infantile spasms. Where available, it is considered by some as an alternative to
ACTH as the drug of first choice. Its principal side effect is its retinal toxicity, with resultant visual field defects that can persist despite withdrawal of the drug. The level of evidence for its efficacy is weaker than that for ACTH and stronger than that of other alternative medications, including valproate, benzodiazepines like Nitrazepam and clonazepam, Topiramate, lamotrigine, zonisamide, pyridoxine, ketogenic diet and intravenous gamma globulin (IVIG). None of these alternative drugs offer uniformly satisfactory results.

\section{Lennox-Gastaut Syndrome}

Treatment of seizures in Lennox-Gastaut syndrome varies according to the preponderant seizure type. For drop attacks (tonic, atonic, or myoclonic atonic seizures), valproate, lamotrigine, or Topiramate have been found to be effective. For patients who have a preponderance of atypical absence seizures, lamotrigine or Ethosuximide are often suitable drugs to try because they are relatively less toxic than many of the alternative drugs. Lamotrigine or valproate should be used if other seizures coexist with absences. Clonazepam and other benzodiazepines are also often helpful for all seizure types, but produce significant sedation. In resistant cases of Lennox-Gastaut syndrome and related epilepsies, rufinamide, zonisamide, felbamate, levetiracetam, acetazolamide, methsuximide, corticosteroids, ketogenic diet, or IVIG can be used.

\section{Other Treatment Modalities}

Epilepsy surgery is often used to treat refractory epilepsy of a number of etiologies, including cortical dysplasia, tuberous sclerosis, polymicrogyria, hypothalamic hamartoma and hemispheric syndromes, such as Sturge-Weber syndrome, hemimegalencephaly, Rasmussen encephalitis and Landau-Kleffner syndrome. Patients with intractable epilepsy resulting from metabolic or degenerative problems are not candidates for resective epilepsy surgery. Focal resection of the epileptogenic zone is the most common procedure. Hemispherectomy is used for diffuse hemispheric lesions; multiple subpial transection, a surgical technique in which the connections of the epileptic focus are partially cut without resecting it, is sometimes used for unresectable foci located in eloquent cortex. In Lennox-Gastaut syndrome, corpus callosotomy is used for drop attacks.

Vagal Nerve Stimulation (VNS) is often used for intractable epilepsies of various types and for seizures of diffuse or multifocal anatomic origin that do not yield themselves to resective surgery.

Focal resection and hemispherectomy result in a high rate $(50-80 \%)$ of seizure freedom. Corpus callosotomy and VNS result in lower rates (5-10\%) of seizure freedom; however, these procedures do result in 
significant reductions in the frequency and severity of seizures, decrease in medication requirements and meaningful improvements in the patient's quality of life in approximately half or more of eligible patients.

\section{Febrile Seizures}

Febrile seizures are the most common seizure disorder in childhood, affecting $2-5 \%$ of children. Febrile seizures are classified as simple febrile seizures (> $80 \%$ ) or Complex Febrile Seizures (CFS). Simple febrile seizure is defined as a short $(<15 \mathrm{~min})$ generalized seizure, not recurring within $24 \mathrm{~h}$, that occurs during a febrile illness, not resulting from an acute disease of the nervous system in a child aged between 6 months and 5 years, with no neurologic deficits and no previous afebrile seizures. It is mostly benign and self-limited, but terrifying event for parents. Complex febrile seizures are focal, or generalized and prolonged seizure, of a duration of greater than $15 \mathrm{~min}$, recurring more than once in $24 \mathrm{~h}$ and/or associated with postictal neurologic abnormalities, more frequently a postictal palsy (Todd's palsy), or with previous neurologic deficits (Yamatogi and Ohtahara, 2003).

In simple febrile seizures, routine EEG and neuroimaging are not recommended. A lumbar puncture should be performed in any child who presents with a seizure and a fever and has meningeal signs and symptoms (e, g, neck stiffness, Kernig and/or Brudzinski signs) or in any child whose history or examination suggests the presence of meningitis or intracranial infection. In general bacterial meningitis is very rare even in children $<12$ months age and lumbar puncture is not necessary in all children (Yamatogi and Ohtahara, 2003; Hattersley and Ashcroft, 2005; AAP, 2011; Sharma, 2013).

Management of febrile seizures includes treatment of acute attack, excluding neuro-infection, finding the cause of fever, prophylaxis for future episodes and parental counseling. Treatment of acute attacks: Simple febrile seizures are mostly self-limiting. For seizures lasting > two minutes, parents can use buccal or nasal midazolam $\left(0.3 \mathrm{mg} \mathrm{kg}{ }^{-1}\right.$, maximum dose $5 \mathrm{mg}$ ) or rectal liquid diazepam $\left(0.5 \mathrm{mg} \mathrm{kg}^{-1}\right.$, maximum $\left.10 \mathrm{mg}\right)$ at home. Antipyretics only improve comfort of child, they don't prevent febrile seizure. Long term prophylaxis therapy only reduces the risk of recurrence of seizure, but does not alter the risk of future epilepsy. It can be intermittent or continuous. Simple febrile seizures have a good prognosis without any residual effect and remit with age. Considering potential side effects of AED, American Academy of Pediatrics does not recommend intermittent or continuous prophylaxis. Intermittent prophylaxis is recommended with at least one of following: (a) Frequent seizures in a short period; 3 or more in 6 months, 4 or more in 1 year, (b) Seizure lasting $>15 \mathrm{~min}$ or requiring drugs to stop seizures. Intermittent prophylaxis with rectal or oral diazepam for 2-3 doses during fever suffices to prevent recurrence. The continuous prophylaxis has a limited role. It is indicated when there is failure of intermittent prophylaxis, or frequent complex febrile seizures. Valproic acid or Phenobarbitone can be used. Valproic acid is preferred over Phenobarbitone due to behavioral side effects of the latter. Carbamazepine and Phenytoin are not useful. Prophylaxis is continued for 2 years seizure free period or 5 years of age, whichever is earlier (Capovilla et al., 2009; AAP, 2011; Sharma, 2013).

Prevention of Epilepsy (Appleton and Gibbs, 2004; Shorvon, 2005; Cross et al., 2013)

There has been little research and little discussion within the literature about this potentially important aspect of epilepsy. In view of the fact that a significant proportion of epilepsy in childhood (up to $30-40 \%$, possibly higher) has a genetic basis and given that for most of these patients genetic 'modification' will never be practicable or clinically justified (irrespective of the ethical dimension), it is unlikely that many of these epilepsies will ever be 'preventable'. For over a decade, it has been claimed that with a greater understanding of the molecular (pathophysiological and genetic) basis of epilepsy, including the relatively newly discovered channelopathies, there would be novel and targeted treatments for the epilepsies, including possible prevention. Unfortunately and not unexpectedly, this has not-and is unlikely-to become a reality within even the next decade. Obviously, where epilepsy is a common and disabling manifestation of a genetic and neurodegenerative disorder, such as the neuronal ceroid lipofuscinoses, genetic modification and/or therapy may be justifiable, although still not necessarily feasible. Nevertheless, there are many situations where the prevention of epilepsy or consequences of epilepsy will be both desirable and achievable; this is particularly applicable, but certainly not exclusively, in the developing world:

- Reduced incidence of high-risk, including teenage pregnancies

- Improved monitoring and ante-natal care of women with high-risk pregnancies

- Improved perinatal care and prevention of any secondary brain damage, particularly in extremely premature and very low birth-weight infants

- Identification of any neuroprotective therapies that may reduce or prevent any secondary brain damage following an initial primary insult in early life 
- Earlier recognition and appropriate treatment of meningitis, encephalitis and intracranial abscesses, particularly in infants and young children

- Improved uptake of childhood immunizations to reduce both the acute encephalopathies and the delayed complications associated with these illnesses

- Improved resuscitation of children with acquired traumatic and non-traumatic brain injury and the prevention of secondary brain damage

- Correct identification and aggressive management of the relatively rare but important epileptic encephalopathies (e.g., West's syndrome, LandauKleffner syndrome), that if unrecognized may potentially cause irreversible cognitive impairment

- Avoidance of using inappropriate AED and specifically drugs that may exacerbate seizures

- Avoidance of the use of multiple AED and in high doses that may have an adverse effect on concentration and short-term memory that, even if transient, may still irreversibly reduce educational potential

- Early rather than late surgery for medically intractable epilepsy, particularly in mesial temporal lobe epilepsy where it may prevent irreversible psychosocial and cognitive (memory) impairment

- Improved pre-, intra-and post-operative neurosurgical access [availability] and care for children requiring a surgical treatment for their epilepsy

- Identification of the child's (and the family's, including siblings') understanding and perceptions of epilepsy to prevent any additional psychopathology within the family

- Improved awareness, knowledge and understanding of epilepsy-what it is and what it is not-amongst all healthcare and education professionals and the public to reduce, if not eliminate, the stigmatization of and not infrequent prejudice against all people with epilepsy

\section{Funding Information}

The authors have no support or funding to report.

\section{Author's Contributions}

The author approved the final manuscript as submitted and agree to be accountable for all aspects of the work.

\section{Ethics}

The author declares no potential conflicts of interest with respect to the research, authorship and/or publication of this article.

\section{References}

AAP, 2011. Febrile seizures: Guideline for the neurodiagnostic evaluation of the child with a simple febrile seizure. Am. Acad. Pediatrics., 127: 389-394. DOI: 10.1542/peds.2010-3318

Aicardi, J. and F. Goutieres, 1978. Neonatal myoclonic encephalopathy (author's transl). Rev. Electroencephal. Neurophysiol. Clin., 8: 99-101. DOI: $10.1016 / \mathrm{S} 0370-4475(78) 80124-5$

Appleton, R. and J. Gibbs, 2004. Epilepsy in Childhood and Adolescence. 2nd Edn., CRC Press, ISBN-10: 1853176540, pp: 160.

Appleton, R.E., A. Freeman and J.H. Cross, 2012. Diagnosis and management of the epilepsies in children: A summary of the partial update of the 2012 NICE epilepsy guideline. Arch Dis. Child, 97: 1073-1076. DOI: 10.1136/archdischild-2012-302822

Aylwad, R.L., 2008. Epilepsy: A review of reports, guidelines, recommendations and models for the provision of care for patients with epilepsy. Clin. Med., 8: 433-438. DOI: 10.7861/clinmedicine.8-4-433

Berg, A.T. and I.E. Scheffer, 2011. New concepts in classification of the epilepsies: Entering the 21st century. Epilepsia, 52: 1058-1062. DOI: 10.1111/j.1528-1167.2011.03101.x

Berg, A.T., S.F. Berkovic, M.J. Brodie, J. Buchhalter and J.H. Cross et al., 2010. Revised terminology and concepts for organization of seizures and epilepsies: Report of the ILAE Commission on Classification and terminology. 2005-2009. Epilepsia, 51: 676685. DOI: 10.1111/j.1528-1167.2010.02522.x

Browne, T.R. and G.L. Holmes, 2008. Handbook of Epilepsy. 1st Edn., Jones and Bartlett Learning, Philadelphia, ISBN-10: 0781773970, pp: 278.

Capovilla, G., M. Mastrangelo, A. Romeo and A. Vigevano, 2009. Recommendations for the management of febrile seizures. Ad hoc task force of LICE guidelines commission. Epilepsia, 50: 2-6. DOI: $10.1111 /$ j.1528-1167.2008.01963.x

Chitre, M., 2013. Pitfalls in the diagnosis and misdiagnosis of epilepsy. Paediatr Child Health, 23: 237-42. DOI: 10.1016/j.paed.2012.11.004

Cross, J.H., G. Kluger and L. Lagae, 2013. Advancing the management of childhood epilepsies. Eur. J. Paediatr Neurol., 17: 334-347. DOI: 10.1016/j.ejpn.2013.02.003

Daroff, R.B., G.M. Fenichel, J. Jankovic and J.C. Mazziotta, 2012. Neurology in Clinical Practice. 6th Edn., Elsevier Health Sciences, Philadelphia, ISBN-10: 1455728071, pp: 2544.

Engel, J.J., 2006. Report of the ILAE classification core group. Epilepsia, 47: 1558-68.

DOI: $10.1111 /$ j.1528-1167.2006.00215.x 
Fisher, R.S., C. Acevedo, A. Arzimanoglou, A. Bogacz and J.H. Cross et al., 2014. ILAE official report: A practical clinical definition of epilepsy. Epilepsia, 55: 475-482. DOI: 10.1111/epi.12550

Glauser, T., E.B. Menachem, B. Bourgeois, A. Cnaan and D. Chadwick et al., 2006. ILAE treatment guidelines: Evidence-based analysis of Antiepileptic drug efficacy and effectiveness as initial monotherapy for Epileptic seizures and syndromes. Epilepsia, 47: 1094-1120.

DOI: $10.1111 / \mathrm{j} .1528-1167.2006 .00585 . \mathrm{x}$

Glauser, T.A. and T. Loddenkemper, 2013. Management of childhood epilepsy. Epilepsy, 3: 656-81. DOI: 10.1212/01.CON.0000431381.29308.85.

Guerrini, R., 2006. Epilepsy in children. Lancet, 367: 499-524. DOI: 10.1016/S0140-6736(06)68182-8

Gupta, S.K., S. Gupta, A. Gupta and H.K. Sharma, 2010. Paediatric Epilepsy: Treatment Updates. JK Science: J. Med. Edu. Res., 12: 210-11.

Hattersley, A.T. and F.M. Ashcroft, 2005. Activating mutations in Kir6.2 and neonatal diabetes: New clinical syndromes, new scientific insights and new therapy. Diabetes, 54: 2503-2513.

DOI: $10.2337 /$ diabetes.54.9.2503

Hauser, W.A. and P.N. Banerjee, 2008. Epidemiology of Epilepsy in Children. In: Pediatric Epilepsy: Diagnosis and Therapy, Pellock, J.M., B.F.D. Bourgeois and W.E. Dodson (Eds.), Demos Medical Publishing, LLC.

Kassaï, B., C. Chiron, S. Augier, M. Cucherat and E. Rey et al., 2008. Severe myoclonic epilepsy in infancy: A systematic review and a meta-analysis of individual patient data. Epilepsia, 49: 343-348. DOI: 10.1016/j.pediatrneurol.2007.08.002

King, M.A., M.R. Newton, G.D. Jackson, G.J. Fitt and L.A. Mitchell et al., 1998. Epileptology of the firstseizure presentation: A clinical, electroencephalographic and magnetic resonance imaging study of 300 consecutive patients. Lancet, 352: $1007-1011$.

DOI: $10.1016 / \mathrm{S} 0140-6736(98) 03543-0$

MEC, 1997. Commission on pediatric epilepsy of the international league against epilepsy. Epilepsia, 38: 1251-1254. PMID: 9579929

Mikati, M.A., 2011. Seizures in Childhood. In: Nelson Textbook of Pediatrics, (Eds)., Kliegman, R.M., B.F. S.T. Stanton, J.W. Geme and N.F. Schor et al., Elsevier Saunders Company.
Obeid, M. and M. Mikati, 2007. Expanding spectrum of paroxysmal events in children: Potential mimickers of epilepsy. Pediatr Neurol., 37: 309-316. DOI: 10.1016/j.pediatrneurol.2007.08.002

Ottman, R., S. Hirose, S. Jain, H. Lerche and I. LopesCendes et al., 2010. Genetic testing in the epilepsies-report of the ILAE Genetics Commission. Epilepsia, 51: 655-70. DOI: $10.1111 / \mathrm{j} .1528-1167.2009 .02429 . \mathrm{x}$

Pellock, J.M., R. Hrachovy, S. Shinnar, T.Z. Baram and D. Bettis et al., 2010. Infantile spasms: A U.S. consensus report. Epilepsia, 51: 2175.

Piña-Garza, E.J. and M.G. Fenichel, 2013. Fenichel's Clinical Pediatric Neurology: A Signs and Symptoms Approach. 1st Edn., Elsevier Health Sciences, London, ISBN-10: 1455723762, pp: 396.

Rudzinski, L.A., J. Jerry and J.J. Shih, 2013. New drug classes for the treatment of partial onset epilepsy: Focus on perampanel. Therapeutic Clin. Risk Manag., 9: 285-293. DOI: 10.2147/TCRM.S37317

Sharma, A., 2013. Seizures and epilepsy in children. Indian J. Pediatr., 80: 925-935. DOI: $10.1007 / \mathrm{s} 12098-013-1173-\mathrm{x}$

Sharma, S., N. Sankhyan, K. Ramesh and S. Gulati, 2011. Child neurology: Epilepsy of infancy with migrating focal seizures. Neurology, 77: 21-24. DOI: $10.1212 /$ WNL.0b013e3182267b4f

Shimomura, K., F. Hrrster, H. De Wet, S.E. Flanagan and S. Ellard et al., 2007. A novel mutation causing DEND syndrome: A treatable channelopathy of pancreas and brain. Neurology, 69: 1342-1349. DOI: 10.1212/01.wnl.0000268488.51776.53

Shorvon, S.D., 2005. Handbook of Epilepsy Treatment: Forms, Causes and Therapy in Children and Adults. 2nd Edn., John Wiley and Sons, Inc., ISBN-10: 9781405131346.

Tamber, M.S. and J.M. Mountz, 2012. Advances in the diagnosis and treatment of epilepsy. Seminars Nuclear Med., 42: 371-386. DOI: 10.1053/j.semnuclmed.2012.06.005

Vigevano, F., 2005. Benign familial infantile seizures. Brain Dev., 27: 172-177. DOI: $10.1016 /$ j.braindev.2003.12.012

Yamatogi, Y. and S. Ohtahara, 2003. Severe epilepsy with multiple independent spike foci. J. Clin. Neurophysiol., 20: 442-448. DOI: 10.1097/00004691-200311000-00006 